\title{
DUAL IMPACT OF COMORBIDITIES AND SYMPTOMS OF CORONAVIRUS ON MENTAL HEALTH DURING COVID-19 PANDEMIC AMONG MALES AND FEMALES IN INDIA: ONLINE CROSS SECTIONAL STUDY
}

\author{
Namrata Puntambekar, Maruti B Desai, Ashwini Kanade, Mangesh S Pednekar, \\ Healis, Sekhsaria Institute for Public Health, Navi Mumbai, Maharashtra 400701, India
}

Correspondence: puntambekarn@healis.org

\begin{abstract}
BACKGROUND:

The novel coronavirus disease 2019(COVID-19) has become a pandemic affecting health and wellbeing worldwide. In addition to the physical health, economic, and social implications, the psychological impacts of this pandemic are increasingly being reported in the scientific literature. Individuals with certain pre-existing comorbidities have been identified as a high-risk group for fatalities of COVID-19 infection. Thus, this study aimed to analyse the association of COVID-19 symptoms and the presence of comorbidities with the mental health of the population during this pandemic.
\end{abstract}

\section{METHOD:}

A cross-sectional web-based online study was conducted from 13thJune to 31 stJuly 2020, and link was circulated using social media platforms. Participants were of age $\geq 18$ and residents of India were included. HERO's scale was used to assess the mental health status. A multivariate logistic regression was performed to examine associations.

\section{RESULTS:}

Out of 1021 eligible individuals (460-females, 561-males), 15.2\% females and $11.2 \%$ males reported poor mental health status. The COVID-19 symptoms such as nausea, vomiting, cough, shortness of breath, runny nose, fever, and sore throat were associated with poor mental health among males, while only nausea, vomiting was associated among females. Also, the presence of any one or more comorbidities was associated with poor mental health across gender.

\section{CONCLUSION:}

Poor mental health was reported by both genders across the study population. Comorbidities and COVID-19 symptoms were significantly associated with poor mental health among males than females. These findings strongly support the need for an infrastructure to comprehend the gender-specific mental well-being as a core component of health across all the sections of Indian society.

\section{KEYWORDS}

COVID-19 pandemic, COVID-19 symptoms, Comorbidities, Mental health, India. 
problems during this pandemic than those without the comorbidities or COVID 19 symptoms.

Mental health issues are responsible for contributing around $13 \%$ of the global burden of disease. [1] Around $80 \%$ of people with mental disorders live in low- and middleincome countries, which account for more than $10 \%$ of the total burden of disease in these countries. Due to this mental health services are already overburdened in many countries. [2]

This pandemic has affected $152,534,452$ individuals globally and India accounts for 19,925, 604.[3] Several regulations were made in place to prevent the spread of the disease. The countries have imposed severe restrictions on movement, likewise, India also went into nationwide lockdown to prevent its spread. The COVID-19 has not impacted physical health, also mental wellbeing across the world. [4] Several psychological problems and significant consequences in terms of mental health problems including stress, anxiety, and depression during the COVID19 outbreak have increasingly emerged. [5] Stress, anxiety, and depression go hand in hand with the COVID-19 pandemic, results from studies done worldwide has shown the increasing prevalence of mental health issues among numerous population groups. [6] Emerging data suggests the presence of comorbidities such as heart disease, hypertension, diabetes, kidney failure, liver, cancer, asthma, and tuberculosis are often associated with an increase in severity and poor prognosis in individuals with positive COVID-19 infection. [7] Restrictions such as isolation, quarantine, and work from home, social distancing have also influenced mental wellbeing. [8]

While everyone is following social distancing and preventive measures amid lockdown, there is an add-on responsibility for people with co-morbid conditions to take the utmost self-care and manage these conditions effectively at home and avoid the risk of COVID 19 infection. [9] Further, the disease outcome for the COVID19 infection is widely related and associated with the presence of comorbidities Thus, it is reasonable to anticipate that individuals with comorbidities such as hypertension, diabetics, and heart disease will face mental health problems such as anxiety, depression, and increased stress. [8] All available evidence states that the existence of comorbidities is associated with a poor outcome with COVID-19 infection.[10] The authors hypothesized that those with comorbidities along with the symptoms of COVID-19 will report more mental health

The most common symptoms of COVID-19 infection as notified by the Centre for Disease Control and Prevention (CDC) are fever, cough, cold, nausea, vomiting, and diarrhoea. The infectious disease outbreak of the COVID-19 (coronavirus) pandemic has had a significant impact not just on the physical health but also on the psychological well-being of communities. [11] This psychological impact is likely to affect the well-being of the individual and community and could persist long after the pandemic. [12]

Looking at the current scenario there is a need to understand the existing mental health problems among the population in the presence of comorbidities and COVID-19 symptoms. This study aimed to assess the association of the presence of comorbidities and COVID-19 symptoms with mental health outcomes among Indians during this pandemic.

\section{METHODOLOGY}

\section{STUDY DESIGN AND PARTICIPANTS RECRUITMENT}

A cross-sectional study was designed to assess the impact of comorbidities and COVID-19 symptoms on the mental health status of the Indian adult population. Face-to-face interviews during the pandemic time were not feasible, therefore, data were collected using a web-based snowball sampling method. The link was shared via social networking sites such as Facebook, Linkedln, Instagram, Healis website, via email, and through WhatsApp. RedCap ('Research Electronic Data Capture') which is a secure web application for building and managing online surveys and databases (13) was used for data collection. All individuals 18 years and older who are residents of India were eligible to participate in the study. Online written consent was obtained from all the participants before they participated in the survey. The study was approved by Healis Institutional Ethical Committee (IEC).

\section{DATA COLLECTION TOOL}

The survey questionnaire comprised 31 close-ended questions which took around approximately 20 minutes to complete the survey. The questions were split into sections such as demographics, symptoms of COVID-19, comorbidities, physical activity, dietary habits, tobacco use, alcohol use, mental health, COVID status, and family 
composition during the pandemic. The Mental health was measured using a reliable and validated HERO's scale questionnaire (14) which contained the following questions:

\section{Hero's scale}

1. I had disturbed sleep often since last 2 months

2. I felt physical pain often since last 2 months

3. I am worrying often since last 2 months

4. I feel sad often since last 2 months

5. I feel angry often since last 2 months

6. I feel tired since last 2 months

7. I feel stressed often since last 2 months

\section{DATA COLLECTION PROCEDURES}

The online survey included a short overview of the study context, purpose, eligibility criteria for the participants, consent form, and directions for answering the questionnaire. Clicking on the survey tab automatically led respondents to the study overview and informed consent page. The survey link was active on the various portals from 13th June to 31st July 2020 and 1291 individuals participated in the survey. A total of 270 individuals were excluded from the study, the common reasons being 141 missing values in the data, 126 used duplicate email ids, and 3 other gender. Thus, 1021 participants were included in the final data analysis.

\section{DATA ANALYSIS}

To subject the collected data for further analysis the study variables were recoded accordingly. In this study, age was recorded as a continuous variable but for analysis, purpose recoded as 18-25 years, 26-35 years, 36-45 years, 46-55 years, and above 55 years. The income variable was as monthly income below Rs.60, 000 and above Rs.60, 000 (11 participants did not reported income). Symptoms of COVID-19 were recoded as no COVID symptoms and any one or more COVID symptoms (Fever, Cough, Shortness of breath, Sore throat, Runny nose, Nausea, Vomiting, and Diarrhoea). The variable 'Comorbidities' were recoded as 'No comorbidities' and 'any one or more comorbidities'. The response option defined as "other comorbidities" included kidney disease, liver disease, cancer, asthma, tuberculosis. The response options in the HERO's scale were binary and recorded as "Yes" and "No". The mental health score was calculated and if the score based on 7 questions was between 0 - 4 it was defined as "Good mental health" and between 5 - 7 was defined as "Poor mental health" (17 participants did not reported mental health status).

Descriptive statistics were calculated for all variables. A categorical variable was compared by Chi-squared test (X2-test) and Fisher's exact test. All statistical analyses were performed and a two-tailed $\mathrm{P}$ value $<0.05$ was considered statistically significant. The association of socioeconomic status, family income, zones, COVID-19 symptoms, and comorbidities with mental health during the COVID-19 pandemic was studied using the multivariate logistic regression model. The logistic regression was adjusted for age, family income, and zones with comorbidities. Further, the regression analysis done to associate the exposure of COVID symptoms to mental health was additionally adjusted for comorbidities. The data were analysed using the Statistical Package for the Social Sciences (SPSS) v25.0.

\section{RESULTS}

The collected data were categorized into zones for analysis- West zone (from Maharashtra, Goa, Gujarat, and Rajasthan), East Zone (Bihar, Orissa and West Bengal), North Zone (Haryana, Jammu \& Kashmir, Punjab, Uttaranchal, Uttar Pradesh, Chandigarh, and Delhi), South Zone (Tamil Nadu, Telangana, Kerala, Andhra Pradesh, and Karnataka), North-East zone (Assam, Manipur and Arunachal Pradesh) and Central zone (Madhya Pradesh and Chhattisgarh). For analysis purposes, these six zones were further categorized into three zones namely, West Zone, Central Zone and all other combined zones.

The survey data (Table 1) showed that the highest number of participants were from the West zone $(68.5 \%)$ and the lowest from the North-East zone (0.5\%). Poor mental health status was reported highest from East zone participants (40.0\%) while lowest from West zone (10.9\%). 
TABLE 1: DISTRIBUTION OF ZONE WISE PERCENTAGE OF PARTICIPANTS AND PREVALENCE OF MENTAL HEALTH STATUS IN INDIA DURING THE COVID-19 PANDEMIC

\begin{tabular}{|c|c|c|c|}
\hline ZONES & STATES & $\begin{array}{l}\text { PARTICIPATION } \\
\text { N }(\%)\end{array}$ & $\begin{array}{l}\text { PREVALENCE OF } \\
\text { OVERALL MENTAL } \\
\text { HEALTH N (\%) }\end{array}$ \\
\hline West Zone & Maharashtra, Goa, Gujarat, and Rajasthan & $699(68.5)$ & $76(10.9)$ \\
\hline Central Zone & Madhya Pradesh and Chhattisgarh & $172(16.9)$ & $24(14.0)$ \\
\hline North Zone & Assam, Manipur, and Arunachal Pradesh & $78(7.6)$ & $13(16.7)$ \\
\hline South Zone & $\begin{array}{l}\text { Tamil Nadu, Telangana, Kerala, Andhra } \\
\text { Pradesh, and Karnataka }\end{array}$ & $46(4.5)$ & $10(21.7)$ \\
\hline East Zone & Bihar, Orissa, and West Bengal & $20(2.0)$ & $8(40.0)$ \\
\hline $\begin{array}{l}\text { North East } \\
\text { Zone }\end{array}$ & $\begin{array}{l}\text { Haryana, Jammu \& Kashmir, Punjab, } \\
\text { Uttaranchal, Uttar Pradesh, Chandigarh, and } \\
\text { Delhi }\end{array}$ & $5(0.5)$ & 0.00 \\
\hline Total & & 1020* & $131(12.84)$ \\
\hline
\end{tabular}

Note:* indicate 1 participant did not reported state

FIGURE 1. SHOWS THE MENTAL HEALTH PROBLEM BY GENDER FROM THE STUDY.

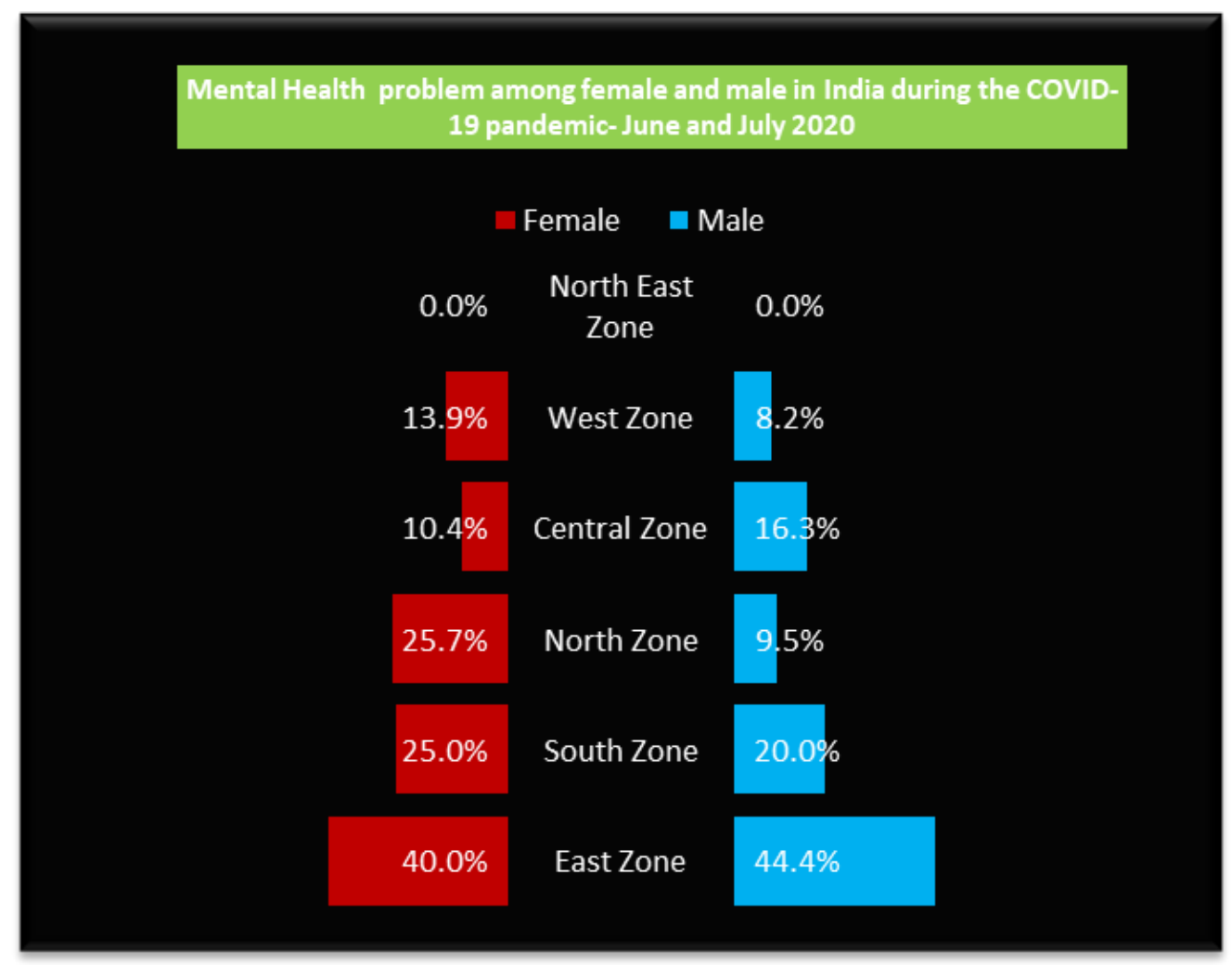


Figure 1 shows that $44.4 \%$ of males and $40.0 \%$ of females from the East zone had poor mental health status.

The data in Table 2 shows the unadjusted logistic regression analysis of the association between socio-demographic factors and mental health status. Females in the age group of 18-25 years reported twelve times higher odds (OR 12.50) of having poor mental health status than the females above 55 years of age. An increasing trend with a significant association in poor mental status was observed among females with decreasing age whereas no such association was found in males. An association with poor mental health was observed among only males in the central zone (OR 2.23), whereas both the genders showed a significant association for all other zones (OR: M- 2.28, F2.14) when compared to the West Zone

TABLE 2 UNADJUSTED LOGISTIC REGRESSION ANALYSIS OF THE ASSOCIATION BETWEEN SOCIO-DEMOGRAPHIC FACTORS AND MENTAL HEALTH STATUS DURING THE COVID-19 PANDEMIC IN INDIA

\begin{tabular}{|c|c|c|c|c|c|c|c|c|c|c|c|}
\hline \multirow{4}{*}{\multicolumn{2}{|c|}{$\begin{array}{l}\text { SOCIO- } \\
\text { DEMOGRAPHIC } \\
\text { FACTORS }\end{array}$}} & \multicolumn{10}{|c|}{ MENTAL HEALTH STATUS } \\
\hline & & \multicolumn{5}{|l|}{ FEMALE } & \multicolumn{5}{|l|}{ MALE } \\
\hline & & \multirow{2}{*}{$\begin{array}{l}\text { GOOD } \\
\text { MENTAL } \\
\text { HEALTH }\end{array}$} & \multirow{2}{*}{$\begin{array}{l}\text { POOR } \\
\text { MENTAL } \\
\text { HEALTH }\end{array}$} & \multirow[t]{2}{*}{ OR } & \multicolumn{2}{|c|}{$95 \%$ C.I. } & \multirow{2}{*}{$\begin{array}{l}\text { GOOD } \\
\text { MENTAL } \\
\text { HEALTH }\end{array}$} & \multirow{2}{*}{$\begin{array}{l}\text { POOR } \\
\text { MENTAL } \\
\text { HEALTH }\end{array}$} & \multirow[t]{2}{*}{ OR } & \multicolumn{2}{|c|}{$95 \%$ C.I. } \\
\hline & & & & & LOWER & UPPER & & & & LOWER & UPPER \\
\hline \multirow[t]{5}{*}{ Age } & $\begin{array}{l}\text { Above } 55 \\
\text { years }\end{array}$ & 40 & 1 & 1 & 1 & 1 & 62 & 7 & 1 & 1 & 1 \\
\hline & $18-25$ & 64 & 20 & $12.50^{*}$ & 1.61 & 96.79 & 37 & 9 & 2.15 & 0.74 & 6.27 \\
\hline & $26-35$ & 127 & 27 & $8.50 *$ & 1.12 & 64.58 & 160 & 14 & 0.78 & 0.30 & 2.01 \\
\hline & $36-45$ & 90 & 18 & $8.0^{*}$ & 1.03 & 62.01 & 166 & 21 & 1.12 & 0.45 & 2.77 \\
\hline & $46-55$ & 67 & 4 & 2.39 & 0.26 & 22.12 & 74 & 11 & 1.32 & 0.48 & 3.60 \\
\hline \multirow[t]{2}{*}{$\begin{array}{l}\text { Family } \\
\text { Income }\end{array}$} & $\begin{array}{l}\text { Below } \\
\text { Rs.60,000 }\end{array}$ & 165 & 24 & 1 & 1 & 1 & 219 & 22 & 1 & 1 & 1 \\
\hline & $\begin{array}{l}\text { Above } \\
\text { Rs.60,000 }\end{array}$ & 217 & 45 & 1.43 & 0.83 & 2.43 & 279 & 39 & 1.39 & 0.80 & 2.42 \\
\hline \multirow[t]{3}{*}{ State } & West Zone & 278 & 46 & 1 & 1 & 1 & 342 & 30 & 1 & 1 & 1 \\
\hline & $\begin{array}{l}\text { Central } \\
\text { Zone }\end{array}$ & 61 & 7 & 0.69 & 0.30 & 1.61 & 87 & 17 & $2.23^{*}$ & 1.17 & 4.22 \\
\hline & $\begin{array}{l}\text { All other } \\
\text { zone }\end{array}$ & 48 & 17 & $2.14^{*}$ & 1.13 & 4.04 & 70 & 14 & $2.28^{*}$ & 1.15 & 4.52 \\
\hline
\end{tabular}

Note- '*' indicated by statistically significant

Table 3 presents the logistic regression analysis of the association between comorbidities and mental health problems adjusted by age, family income, and zones. The presence of one or more comorbidities was found to be significantly associated with poor mental health status among males and females. Heart disease, diabetes, hypertension, and 'other diseases' were associated with a poor mental health status among males.
Table 4 presents the logistic regression analysis of the association between symptoms of COVID 19 and mental health status adjusted for age, family income, zones, and co-morbidities. All except diarrhoea COVID-19 symptoms nausea-vomiting, cough, shortness of breath, runny nose, fever, and sore throat were associated with poor mental health status among males. 
TABLE 3: LOGISTIC REGRESSION ANALYSIS OF THE ASSOCIATION BETWEEN COMORBIDITIES AND MENTAL HEALTH STATUS DURING THE COVID-19 PANDEMIC IN INDIA

\begin{tabular}{|c|c|c|c|c|c|c|c|c|c|c|c|}
\hline \multirow{4}{*}{\multicolumn{2}{|c|}{ COMORBIDITIES }} & \multicolumn{10}{|c|}{ MENTAL HEALTH STATUS } \\
\hline & & \multicolumn{5}{|l|}{ FEMALE } & \multicolumn{5}{|l|}{ MALE } \\
\hline & & \multirow{2}{*}{$\begin{array}{l}\text { GOOD } \\
\text { MENTAL } \\
\text { HEALTH }\end{array}$} & \multirow{2}{*}{$\begin{array}{l}\text { POOR } \\
\text { MENTAL } \\
\text { HEALTH }\end{array}$} & \multirow[t]{2}{*}{ OR } & \multicolumn{2}{|c|}{$95 \%$ C.I. } & \multirow{2}{*}{$\begin{array}{l}\text { GOOD } \\
\text { MENTAL } \\
\text { HEALTH }\end{array}$} & \multirow{2}{*}{$\begin{array}{l}\text { POOR } \\
\text { MENTAL } \\
\text { HEALTH }\end{array}$} & \multirow[t]{2}{*}{ OR } & \multicolumn{2}{|l|}{$95 \%$ C.I. } \\
\hline & & & & & LOWER & UPPER & & & & LOWER & UPPER \\
\hline \multirow[t]{2}{*}{$\begin{array}{l}\text { Comorbiditie } \\
\text { s }\end{array}$} & $\begin{array}{l}\text { No } \\
\text { comorbidities }\end{array}$ & 335 & 57 & 1 & 1 & 1 & 391 & 29 & 1 & 1 & 1 \\
\hline & $\begin{array}{l}\text { Any } 1 \text { or } \\
\text { more } \\
\text { comorbidities }\end{array}$ & 53 & 13 & $2.72^{*}$ & 1.26 & 5.89 & 108 & 33 & $5.79 *$ & 2.99 & 11.21 \\
\hline $\begin{array}{l}\text { Heart } \\
\text { Disease }\end{array}$ & Yes & 4 & 0 & - & - & - & 10 & 9 & $\begin{array}{l}13.8 \\
7^{*}\end{array}$ & 3.70 & 51.94 \\
\hline Diabetes & Yes & 17 & 4 & 2.67 & 0.75 & 9.54 & 43 & 19 & $9.12 *$ & 3.87 & 21.45 \\
\hline Hypertension & Yes & 23 & 2 & 2.02 & 0.38 & 10.85 & 66 & 22 & $5.94^{*}$ & 2.77 & 12.72 \\
\hline
\end{tabular}

Note- Logistic regression analysis adjusted by age, family income, zones; No comorbidities is the reference category; '*' indicated by statistically significant; '-' indicated by inadequate numbers

TABLE 4: LOGISTIC REGRESSION ANALYSIS OF THE ASSOCIATION BETWEEN COVID-19 SYMPTOMS AND MENTAL HEALTH STATUS DURING THE COVID-19 PANDEMIC IN INDIA

\begin{tabular}{|c|c|c|c|c|c|c|c|c|c|c|c|}
\hline \multirow{4}{*}{\multicolumn{2}{|c|}{ COVID-19 SYMPTOMS }} & \multicolumn{10}{|c|}{ MENTAL HEALTH STATUS } \\
\hline & & \multicolumn{5}{|l|}{ FEMALE } & \multicolumn{5}{|l|}{ MALE } \\
\hline & & \multirow{2}{*}{$\begin{array}{l}\text { GOOD } \\
\text { MENTAL } \\
\text { HEALTH }\end{array}$} & \multirow{2}{*}{$\begin{array}{l}\text { POOR } \\
\text { MENTAL } \\
\text { HEALTH }\end{array}$} & \multirow[t]{2}{*}{ OR } & \multicolumn{2}{|c|}{$95 \%$ C.I. } & \multirow{2}{*}{$\begin{array}{l}\text { GOOD } \\
\text { MENTAL } \\
\text { HEALTH }\end{array}$} & \multirow{2}{*}{$\begin{array}{l}\text { POOR } \\
\text { MENTAL } \\
\text { HEALTH }\end{array}$} & \multirow[t]{2}{*}{ OR } & \multicolumn{2}{|c|}{$95 \%$ C.I. } \\
\hline & & & & & LOWER & UPPER & & & & $\begin{array}{l}\text { LOWE } \\
\mathrm{R}\end{array}$ & UPPER \\
\hline \multirow[t]{2}{*}{ Symptoms } & $\begin{array}{l}\text { No } \\
\text { symptoms }\end{array}$ & 323 & 49 & 1 & 1 & 1 & 428 & 37 & 1 & 1 & 1 \\
\hline & $\begin{array}{l}\text { Any } 1 \text { or } \\
\text { above } \\
\text { symptoms }\end{array}$ & 62 & 21 & 1.69 & 0.92 & 3.13 & 64 & 23 & $3.43^{*}$ & 1.83 & 6.40 \\
\hline $\begin{array}{l}\text { Nausea, } \\
\text { vomiting }\end{array}$ & Yes & 9 & 6 & $3.37^{*}$ & 1.09 & 10.41 & 3 & 3 & $7.86^{*}$ & 1.30 & 47.69 \\
\hline $\begin{array}{l}\text { Cough } \\
\text { (new or } \\
\text { worsening) }\end{array}$ & Yes & 15 & 3 & 0.88 & 0.23 & 3.45 & 18 & 13 & $7.16^{*}$ & 2.97 & 17.23 \\
\hline $\begin{array}{l}\text { Shortness of } \\
\text { breath (new } \\
\text { or } \\
\text { worsening) }\end{array}$ & Yes & 5 & 4 & 3.04 & 0.68 & 13.63 & 6 & 3 & $5.30^{*}$ & 1.13 & 24.88 \\
\hline Runny nose & Yes & 19 & 5 & 1.50 & 0.51 & 4.41 & 22 & 9 & $5.26^{*}$ & 2.07 & 13.32 \\
\hline
\end{tabular}




\begin{tabular}{|l|l|l|l|l|l|l|l|l|l|l|l|}
\hline Fever & Yes & 19 & 3 & 0.84 & 0.23 & 3.12 & 19 & 10 & $4.48^{*}$ & 1.79 & 11.25 \\
\hline Sore throat & Yes & 19 & 8 & 2.44 & 0.95 & 6.31 & 27 & 12 & $3.83^{*}$ & 1.65 & 8.88 \\
\hline Diarrhoea & Yes & 6 & 4 & 2.87 & 0.75 & 10.99 & 8 & 3 & 2.25 & 0.50 & 10.09 \\
\hline
\end{tabular}

Note- Logistic regression analysis adjusted by age, family income, zones, comorbidities; 'no symptoms' is the reference category; '*' indicated by statistically significant odds ratio

\section{DISCUSSION}

WHO estimates that about 7.5 percent of Indians suffer from some mental health problem and predicts that by end of the year 2020 roughly 20 percent of Indian population will suffer from mental diseases. According to the numbers, 56 million Indians suffer from depression and another 38 million Indian population suffer from anxiety disorders. [15] The current global pandemic has posed unprecedented circumstances for the communities. These circumstances which were enforced to prevent and protect the population have resulted in a global mental health crisis. The impact of the COVID-19 pandemic on mental health is complex, varied, and wide-ranging, affecting all parts of societies and individuals. In addition, the presence of comorbidities like heart, lung disease, diabetes, and other chronic diseases which makes the population more vulnerable to COVID-19 has also added to the mental health burden. [16] Recognizing that there is an existing significant mental health burden worldwide with limited access to mental health services the pandemic has challenged the health care services. [17]

The present study confirms that the presence of comorbidities and symptoms of coronavirus are significantly associated with mental health status among the Indian population. An epidemic of COVID-19 not only impacted physical well-being but also caused disruption, anxiety, and stress which has resulted in mental health problems among the population. The rapid spread of COVID 19 infection resulted in the enforcement of regulations to stop the further spread of the disease. The nation-wide lockdown, isolation, and quarantine of affected persons, social distancing, closure of educational institutes, offices/workplaces, and entertainment places all consigned people to stay in their homes. [18] In the literature, it has been stated that the fear of COVID -19 infection, loss of job, strict lockdown, deaths, and lack of a caregiver and family support, meant the population experiencing a mix of emotions that can potentially damage their mental health problem. [19] Studies have also identified that separation from loved ones, loss of freedom, dullness, and uncertainty can cause a worsening in an individual's mental health status. [20]

The presence of comorbidities is an important predictor of poor mental health among individuals. [21] This study confirms the findings reported in the literature that one or more comorbidities like hypertension, diabetics, cardiovascular, and other chronic diseases increases the mental health problems like stress, anxiety, and depression which further leads to mental health problems. [22] Evidence also reported that individuals have poor mental health due to the disease itself and have expressed worries about the chronic and potential long-term problems of the disease. [23] The present study highlights that mental health problems are exaggerated at a higher end in the pandemic situation than the regular disease scenario.

This signifies the occurrence of prevalent mental health burdens in the current pandemic. The simultaneous existence of comorbid non-communicable diseases (NCDs) like hypertension, diabetes, and other chronic illnesses and psychological co-morbidities like stress, anxiety, and depression results in individuals into a 'vicious' cycle. [24] In the current study, we have identified gender-specific responses between relationships of comorbidities with mental health status during this pandemic. The study reported males who have heart disease, diabetes, and hypertension, reported higher odds of poor mental health status while no such association was reported among females. The study indicates further representative national study to identify gender-based differences and ways to address them.

The most common reported symptoms by the CDC for COVID-19 are fever or chills, cough, shortness of breath or difficulty breathing, fatigue, muscle or body aches, headache, new loss of taste or smell, sore throat, congestion or runny nose, nausea or vomiting, and diarrhoea. In the present study, the overall prevalence of having any one or more COVID-19 symptoms was $25.8 \%$ among the participants. Additionally, the study highlights three times the odds of poor mental health status among 
the participants who reported COVID-19 symptoms than the non-symptomatic ones. Similarly, a study showed an impact of COVID-19, 16-18\% of participants reported anxiety and depression. [25] However the other studies did not see the symptom-wise association on mental health in the present study that has explored the symptoms and predicted the mental health status of the participants. In the present study the adjustment of comorbidities was highlighted, poor mental health status was still at a higherend denoting the reason being the current pandemic situation. The gender-based findings in this study have identified that various Covid-19 symptoms were associated differently with poor mental health status which needs careful consideration in future planning.

The following Figure 2 displays a conceptual framework of the presence of comorbidities and COVID-19 symptoms and its interrelationships of outcomes of mental health of individuals in the context of a pandemic. The current situation of COVID-19 is exercising a strain on the individuals and the families who may be directly affected by the virus or hit indirectly due to fear of infection, social isolation, lockdown, or restrictions illustrated in the below mentioned conceptual map (Figure 2).

FIGURE 2. CONCEPTUAL FRAMEWORK OF THE PRESENCE OF COMORBIDITIES AND COVID-19 SYMPTOMS AFFECTING MENTAL HEALTH

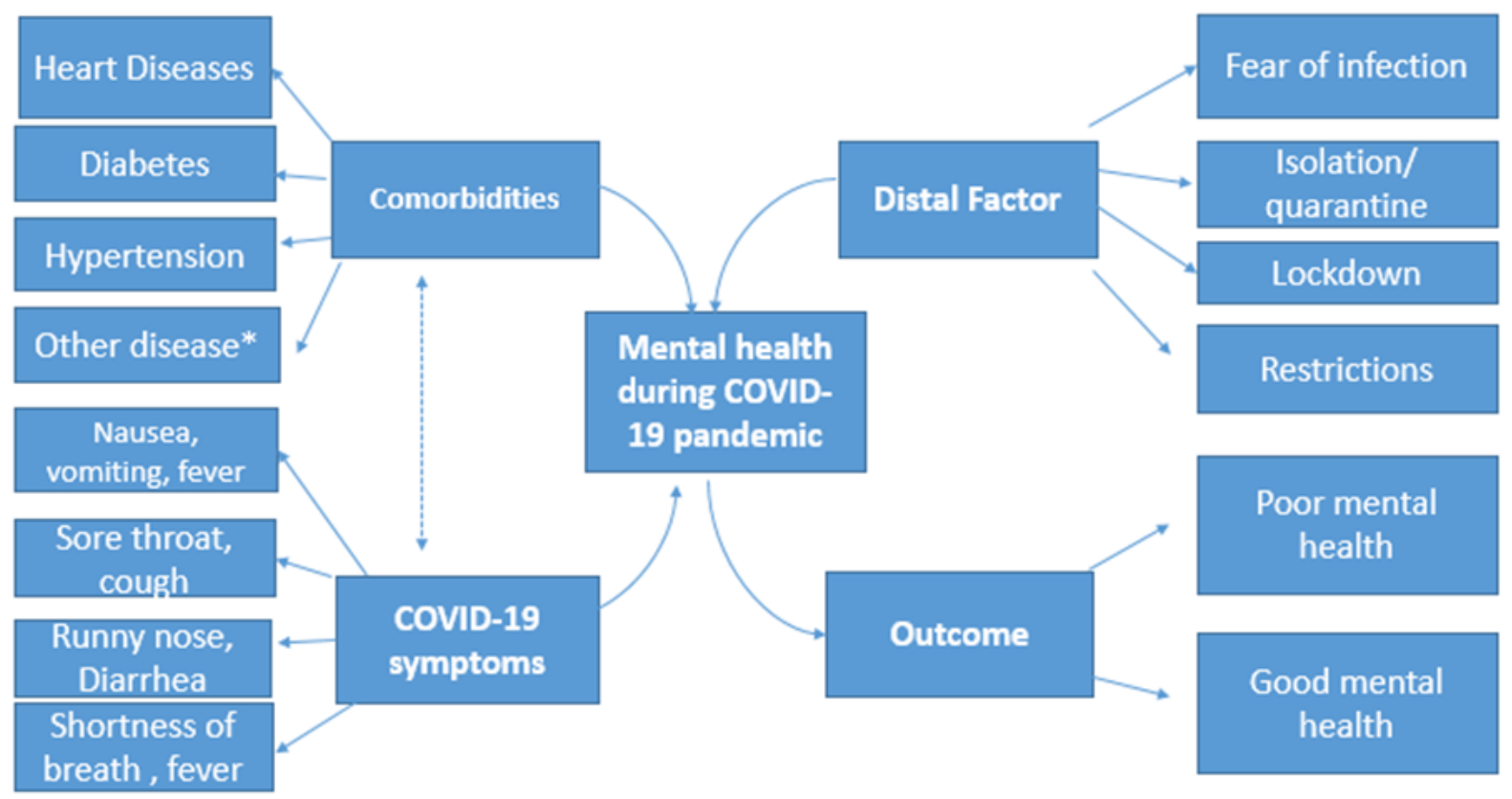

*Other disease includes kidney disease, liver disease, cancer, asthma, tuberculosis

Identifying the poor mental status among the Indian population facing the pandemic highlights the need to address these issues in the existing COVID-19 management protocols. Outcome-based strategies to tackle the mental health problems due to the existing pandemic are the way forward. The healthcare providers can explore various digital programs/internet platforms for telecommunication to reach out to the appropriate population during this pandemic. Public health policymakers can incorporate mental health outreach into growing COVID-19 protocols, particularly to high-risk populations that have existing chronic diseases. Furthermore, non- communicable disease program targeting the comorbid population should include preventive health messages related to susceptibility to COVID 19 infection. The pandemic put forward the demand for a global public health campaign to raise awareness of mental health and its related components to the global pandemic. The study highlights the requirement for more gender-based mental health research to design specific gender-targeted problembased strategies. Along with this media and internet-based portals can be utilized to spread information about the effect of COVID -19 on mental health status. These channels can also be exploited to reach the mass at the 
larger level and render mental health services. The survey findings also strongly underpin the need for an infrastructure to promote and support mental well-being as a core component of health along with the physical wellbeing for both genders across the population.

\section{LIMITATION OF THE STUDY}

This was a cross-sectional self-reported online survey that may be subject to recall bias and the direction of the association may not be ascertained similar to cohort or randomised control study designs. The study limitations include the participants' recruitment methods wherein only internet users were captured and the language of administration of the questionnaire was in English. This denotes the non-representation of non-internet users or those who do not read and write in English. Furthermore, the survey was limited to the set of the population which had access to social media platforms. As it was also not feasible to define a sampling frame for this study we used the snowball sampling method. However, the sample may not be representative of the population and the study results would apply only to a population similar to the study sample.

\section{CONCLUSION}

COVID-19 pandemic is a worldwide public health emergency with extensive effect on the mental health of individuals. The present study shows that individuals with the presence of comorbidities and COVID-19 symptoms have a higher risk of getting impacted in this pandemic and are most vulnerable to mental health problems. Moreover, the impact has been observed among both genders. Taken together, the existing comorbidities and the mental health problems inform a psychiatric pandemic is co-occurring with the COVID-19 symptoms, which is becoming a global health challenge. This evidence should be widely communicated with the general public and global health community to prevent the mental health consequences of COVID-19 across gender as well. Nevertheless, it is essential to identify highly vulnerable persons and connect them to required special care, whereas access to mental health facilities and resources should be promoted, aiming for positive mental health outcomes. To conclude, evidencebased policymaking and practice should be adopted to guide how those mental health challenges can be mitigated in different contexts amidst the COVID-19 pandemic and future public health emergencies.

\section{References:}

1. Jacob KS, Patel V. Classification of mental disorders: A global mental health perspective. Lancet [Internet]. 2014;383(9926):1433-5. Available from: http://dx.doi.org/10.1016/s0140-6736(13)62382-X

2. Primary $\mathrm{WHO}$, Mental $\mathrm{C}$, Factsheet $\mathrm{H}$. What is primary care mental health?: WHO and Wonca Working Party on Mental Health. Ment Health Fam Med [Internet]. 2008;5(1):9-13. Available from:

http://www.ncbi.nlm.nih.gov/pubmed/22477841\%0Ah ttp://www.pubmedcentral.nih.gov/articlerender.fcgi? artid=PMC2777553

3. WHO. WHO Coronavirus (COVID-19) Dashboard. 2021. p. 1-8.

4. Jakovljevic M, Bjedov S, Jaksic N, Jakovljevic I. Covid19 pandemia and public and global mental health from the perspective of global health security. Psychiatr Danub. 2020;32(1):6-14.

5. Duan L, Zhu G. Psychological interventions for people affected by the COVID-19 epidemic. The Lancet Psychiatry. 2020;7(4):300-2.

6. Ji D, Ji YJ, Duan XZ, Li WG, Sun ZQ, Song XA, et al. Prevalence of psychological symptoms among Ebola survivors and healthcare workers during the 2014-2015 Ebola outbreak in Sierra Leone: A cross-sectional study [Prevalencia de síntomas psicológicos entre los supervivientes del ébola y los trabajadores sani. Oncotarget. 2017;8(8):12784-91.

7. Kumar A, Misra A. Impact of COVID-19 and comorbidities on health and economics: Focus on developing countries and India. Diabetes Metab Syndr [Internet]. 2020;14(6) (January):1625-30. Available from: 10.1016/j.dsx.2020.08.032

8. Brooks S, Webster R, Smith L, Woodland L, Wessely S, Greenberg N. The psychological impact of quarantine and how to reduce it: rapid review of the evidence [revista en Internet] 2020 [acceso 28 de enero de 2021]; 395(10227): 912-920. Lancet [Internet]. 2020;395(January):912-20. Available from: https://www.ncbi.nlm.nih.gov/pmc/articles/PMC71589 42/pdf/main.pdf

9. Baroque A, Baroque GA. Mental Health in the times of COVID-19 Pandemic Guidelines for General Medical and Specialised Mental Health Care Settings. Philipp J Allied Heal Sci [Internet]. 2020;4(1). Available from: 
Mental Health in the times of COVID-

19_Pandemic_Guidelines_for_General_Medical_and_S

pecialised_Mental_Health_Care_Settings

10. Sanyaolu A, Okorie C, Marinkovic A, Patidar R, Younis $K$, Desai $P$, et al. Comorbidity and its Impact on Patients with COVID-19. SN Compr Clin Med. 2020;2(8):1069-76.

11. Chew QH, Wei KC, Vasoo S, Sim K. Narrative synthesis of psychological and coping responses towards emerging infectious disease outbreaks in the general population: practical considerations for the COVID-19 pandemic. J Clin Psychiatry. 2020;81(6):350-6.

12. James PB, Wardle J, Steel A, Adams J. Post-Ebola psychosocial experiences and coping mechanisms among Ebola survivors: a systematic review. Trop Med Int Heal. 2019;24(6):671-91.

13. Harris PA, Taylor R, Thielke R, Payne J, Gonzalez N, Conde JG. Research electronic data capture (REDCap)-A metadata-driven methodology and workflow process for providing translational research informatics support. J Biomed Inform. 2009;42(2):37781.

14. Buysse DJ, Yu L, Moul DE, Germain A, Stover A, Dodds $N E$, et al. HERO Daily Experiences Index. Sleep [Internet]. 2010;33(6):781-92. Available from: https://www.nlm.nih.gov/dr2/HERO_Daily_Impact_Ind $\underline{\text { ex.pdf }}$

15. NDTV. World Mental Health Day 2020: In Numbers, The Burden of Mental Disorders in India. NDTV/ Swachhindia [Internet]. 2020;1-11. Available from: https://swachhindia.ndtv.com/world-mental-healthday-2020-in-numbers-the-burden-of-mental-disordersin-india-51627/

16. Zhao Q, Meng M, Kumar R, Wu Y, Huang J, Lian N, et al. The impact of COPD and smoking history on the severity of COVID-19: A systemic review and metaanalysis. J Med Virol. 2020;92(10):1915-21.

17. United Nations. Policy Brief: Covid-19 and the Need for Action on Mental Health. Policy Br COVID-19 Need Action Ment Heal. 2020;1-17.

18. Javed B, Sarwer A, Soto EB, Mashwani ZUR. Is Pakistan's Response to Coronavirus (SARS-CoV-2) Adequate to Prevent an Outbreak? Front Med. 2020;7(April):7-10.

19. Ramanathan K, Antognini D, Combes A, Paden M, Zakhary $B$, Ogino $M$, et al. How mental health care should change as a consequence of the COVID-19 pandemic. The Lancet Psychiatry. 2020;7(9):813-24.

20. Sanchez Nicolas E. WHO warning on lockdown mental health. EU Obs [Internet]. 2020;1-6. Available from: https://euobserver.com/coronavirus/147903

21. Sartorious N. Comorbidity of mental and physical diseases: a main challenge for medicine of the $21 \mathrm{st}$ century. Shanghai Arch Psychiatry 2013, [Internet]. 2013;25(2):68-9. Available from:

http://ci.nii.ac.jp/lognavi? name=nels\&lang=jp\&type= pdf\&id=ART0004852131

22. Verma M, Grover S, Tripathy JP, Singh T, Nagaraja SB, Kathirvel S, et al. Co-existing non-communicable diseases and mental illnesses amongst the elderly in Punjab, India. Eur Endocrinol. 2019;15(2):106-12.

23. Moukaddam N, Shah A. Psychiatrists beware! The impact of COVID-19 and pandemics on mental health. Psychiatr Times [Internet]. 2020;37(3):11-2. Available from: https://www.psychiatrictimes.com/view/psychiatristsbeware-impact-coronavirus-pandemics-mentalhealth

24. Tripathy JP, Thakur JS, Jeet G, Chawla S, Jain S. Alarmingly high prevalence of hypertension and prehypertension in North India-results from a large crosssectional STEPS survey. PLOS One. 2017;12(12):1-16.

25. Rajkumar RP. COVID-19 and mental health: A review of the existing literature. Asian J Psychiatr [Internet]. 2020;52(March):1-5. Available from: https://www.ncbi.nlm.nih.gov/pmc/articles/PMC71514 $15 /$ 